\title{
Soxhlet Extraction versus Hydrodistillation Using the Clevenger Apparatus: A Comparative Study on the Extraction of a Volatile Compound from Tamarindus indica Seeds
}

\author{
Kehinde Oluwakemi Fagbemi (D), Daniel Ayandiran Aina, \\ and Olufunmiso Olusola Olajuyigbe $\mathbb{C}$ \\ Department of Microbiology, School of Science and Technology, PMB 4005, Babcock University, Ilisan-Remo, Ogun State, Nigeria \\ Correspondence should be addressed to Kehinde Oluwakemi Fagbemi; olakemik4u.kf@gmail.com
}

Received 19 May 2021; Revised 25 October 2021; Accepted 30 October 2021; Published 2 December 2021

Academic Editor: Claudio Cameselle

Copyright (c) 2021 Kehinde Oluwakemi Fagbemi et al. This is an open access article distributed under the Creative Commons Attribution License, which permits unrestricted use, distribution, and reproduction in any medium, provided the original work is properly cited.

\begin{abstract}
The present study aims to compare two traditional extraction techniques. A volatile compound from Tamarindus indica seed was obtained with Soxhlet extraction (SE) and hydrodistillation using the Clevenger apparatus (HDC). The extraction yield and chemical composition of the essential oil samples were compared. Both oils extracted were analyzed with GC-MS, and forty-one chemical compounds were identified in essential oil components from SE while forty chemical compounds were found in the HDC-extracted oil sample. The major essential oil components present in both the SE and HDC method are cis-vaccenic acid, 2-methyltetracosane, beta-sitosterol, 9,12-octadecadienoic acid (Z, Z)-, and $n$-hexadecanoic acid in varying concentrations. Moreover, the essential oils obtained by both methods look similar quantitatively but differ qualitatively. The HDC method produced more oxygenated compounds that contribute to the fragrance of the oil. The major constituents observed in the essential oil extracted by SE methods include cis-vaccenic acid (17.6\%), beta-sitosterol (12.71\%), 9,12-octadecadienoic acid (Z, Z)- (11.82\%), n-hexadecanoic acid (8.16\%), 9,12-octadecadienoic acid, methyl ester (5.84\%), oleic acid (4.54\%), and 11-octadecenoic acid and methyl ester (3.94\%). However, in the hydrodistillation technique, the oil was mostly composed of 9,12-octadecadienoic acid (Z, Z)- (23.72\%), cis-vaccenic acid (17.16\%), n-hexadecanoic acid (11.53\%), beta-sitosterol (4.53\%), and octadecanoic acid (3.8\%). From the data obtained, HDC seems to be a better method for extraction of Tamarindus indica essential oil compared to the Soxhlet extraction apparatus.
\end{abstract}

\section{Introduction}

The earth is endowed with varieties of medicinal plants which have been a great source of many active compounds used in pharmaceutical and food industries [1]. Medicinal plants' usage is attributed to their bioactive ingredients. Plants such as Tamarindus indica have been a major source of many novel compounds used for drug development [2]. Other plants with such desirable bioactive compounds for medicinal purposes include Erythrina abyssinica, Aloe vera, Albizia coriaria, Azadirachta indica [3]; Boswellia corteri [4], and Oroxylum indicum (L.) [5].

Tamarindus indica L. generally known as tamarind is the third largest family of flowering plants with 727 genera identified. It belongs to the subfamily Caesalpinioideae of the family Leguminosae (Fabaceae) [6, 7]. Tamarind has been extensively used for numerous indigenous medicinal purposes and contributes to food security in sub-Saharan Africa. It possesses several properties which include hepatoprotective activity, antiasthmatic activity, and laxative such as anti-inflammatory activity and antibacterial activity among others [8]. Moreover, other valuable bioproducts such as essential oil can be obtained from tamarind plant. Hence, it has been reported to be one of the most significant multipurpose trees from the tropics [9].

Essential Oils (EOs) are composite combinations of lowmolecular-weight volatile compounds extracted from plants parts such as flowers, leaves, seeds, fruits, and stems of 
aromatics plants [10]. Essential oils, among other usage, can be used to prolong fruit shelf life, thus maintaining their postharvest quality. The major ingredients which are responsible for the distinctive aroma and biological activities of EOs are the terpenoids and phenylpropanoids [10]. Furthermore, EOs are characterized by their hydrophobicity nature. Several techniques are used for the extraction of Eos. These include supercritical fluid extraction, subcritical extraction liquid, solvent-free microwave extraction, hydrodistillation, steam distillation, hydrodiffusion, Soxhlet extraction, and solvent extraction [11]. The composition of the EOs may differ from one another depending on the extraction techniques applied. The extraction technique and the operating conditions could significantly impact on process performance and ultimately the extraction efficiency [12]. Hence, a suitable extraction technique is imperative to obtain a value-added product like essential oil. Currently, there is a scarcity of literature on the choice of extraction approach for the extraction of EOs from Tamarindus indica plant. This study highlights a suitable extraction method to obtain EOs from Tamarind seeds. Evidently, the Tamarindus indica structure becomes more accessible and solubilizes to obtain essential oil units [13]. Extraction methods that will be used in this study include Soxhlet extraction and hydrodistillation using the Clevenger apparatus.

Soxhlet extraction is one of the traditional techniques that have been extensively used for the extraction of bioactive compounds from numerous natural sources. For several decades, this technique has been consistently functional in various analytical processes in relation to the extraction of bioactive compounds [14]. One of the main advantages of the Soxhlet extraction technique is that compounds with average to low solubility can be extracted with this technique [15]. To obtain a satisfactory yield from this technique as well as to avert the loss of volatile compounds, the right choice of solvent is imperative. Also, the type of solvent used in this technique is suggestive of the polarity of the compounds pulled out. The extraction period is typically long, thereby resulting in the destruction of some thermolabile compounds [16].

Hydrodistillation is another conventional method which uses water or steam for the extraction of bioactive compounds, mostly essential oils. This technique is regularly performed via a setup recognized as the Clevenger apparatus or simple steam distillation. In the Clevenger apparatus, the hydrated sample is heated to vaporize volatile constituents, while in the steam distillation approach, steam is passed through a bed of the sample. In both methodologies, two layers (aqueous and oil-rich) are achieved and oil can be further separated via separating funnels. From economical point of view, this technique does not require the use of organic solvents [17], making it a desirable option when extraction cost is of importance. Hydrodistillation involves three main physicochemical processes: hydrodiffusion, hydrolysis, and heat decomposition [18].

In view of that mentioned above, the choice of extraction technique is critical to the viability of the volatile compound to be extracted and obtaining a desirable yield. Many extraction techniques resulted in a very low concentration of the extracted compound; therefore, it is very vital to explore the efficacy of different extraction processes to discover the most preferable technique for the extraction of essential oils from plant material such as Tamarindus indica [19]. There is a dearth of studies on the usage of Soxhlet and hydrodistillation conventional methods on EO extraction from tamarind seed. Therefore, the main objectives of this study are to access Soxhlet and hydrodistillation (with the Clevenger) convectional techniques for the extraction of essential oil from Tamarindus indica seed as well as compare the quality of the extracted essential oil using gas chromatography coupled with mass spectrometry (GC-MS) for identification of compounds present.

\section{Materials and Methods}

Tamarind fruits were purchase from a market in Michika, Yola, Adamawa state, Nigeria, in April 2019. The pulp was removed in order to get the seed. Seeds obtained were sundried. The dried seeds were crushed and pulverised to powder. The particle sizes range from 0.05 to $2.0 \mathrm{~mm}$.

2.1. Preparation of Extracts. Tamarind fruits were collected from Yola, Adamawa state, Nigeria. They were botanically authenticated by a taxonomic (Dr. Nodaz George) from the University of Lagos herbarium with a voucher no. LUH: 8772 and was deposited at the herbarium. The fruits were sun-dried and peeled to collect the seeds. The moisture content of the seed was determined before pulverising. All reagents used for this study were of the highest analytical grade and were obtained from Sigma-Aldrich Chemical Company (Germany).

\subsection{Extraction Process}

2.2.1. Soxhlet Extraction Method (SE). A total of $100 \mathrm{~g}$ of the pulverised tamarind seeds was kept in a thimble holder before placing it into the Soxhlet apparatus. Petroleum ether $(500 \mathrm{ml})$ was dispensed in a round-bottom flask to initiate the extraction process. The extraction was carried out for $6 \mathrm{~h}$, at temperature between 30 and $60^{\circ} \mathrm{C}$. When the solution in the thimble was clear, it signified that the oil was completely extracted from the raw seed and the apparatus was switched off. The collected solvent and the oil were placed in a water bath to remove the solvent, and the oil was golden yellowish with high viscosity [20].

\subsubsection{Hydrodistillation with the Clevenger (HDC).} Pulverised seeds of tamarind were subjected to hydrodistillation with the Clevenger under optimal operational conditions with a temperature of $40^{\circ} \mathrm{C}$ as described by Elyemni et al. [21]. One hundred grams $(100 \mathrm{~g})$ of pulverised tamarind seed was mixed with $800 \mathrm{ml}$ of distilled water. The distillation process was performed for $3 \mathrm{~h}$, and the obtained essential oil was collected and dehydrated using anhydrous sodium sulphate. 
2.2.3. Moisture Content. The moisture content of the seed was determined before pulverising and calculated as follows.

Dry basis moisture content $\left(M_{d}\right)$ is described by the percentage equivalent of the ratio of the weight of water $\left(W_{w}\right)$ to the weight of the dried sample $\left(W_{d}\right)$ :

$$
M_{d}=\left(\frac{W_{w}}{W_{d}}\right) \times 100
$$

2.2.4. Extraction Yields. For each extraction technique, the total yield is defined as gram of oil extracted per $\mathrm{kg}$ of the pulverised material seed into the extraction apparatus.

The extraction yields of the essential oils obtained from both methods were calculated as follows:

$$
\text { Extraction yield }(\%)=\frac{\text { Mass of extracted oil }}{\text { Mass of pulverised seed }} \times 100 \text {. }
$$

2.3. Gas Chromatography-Mass Spectrometry (GC-MS) Analysis. GC-MS analysis was carried out on GCMSQP2010 (Shimadzu, Tokyo, Japan) mass selective detector equipped with an AOC-20i autosampler injector and fitted with a BP-20 capillary column (SGE International, Ringwood, Australia) $(30 \mathrm{~m}$ length $\times 0.25 \mathrm{~mm}$ internal diameter; $0.25 \mu \mathrm{m}$ film thickness, polyethylene glycol, TPA treated). The samples were diluted as $10 \mu \mathrm{L}$ in $2 \mathrm{~mL}$ DCM (Merck KGaA, Darmstadt, Germany, HPLC grade); sample injection volume was $1 \mu \mathrm{L}$. Helium (99.99\% pure, M/s. J.K. Enterprise, Nasarala, Hoshiarpur, Punjab, India) was used as carrier gas with $1.28 \mathrm{~mL} / \mathrm{min}$ flow rate, linear velocity $46.3 \mathrm{~cm} /$ second, column pressure: $144.4 \mathrm{kPa}$, and a split mode ratio of $15: 1$. The oven temperature was programmed as mentioned in the GC. The injector port temperature was maintained at $250^{\circ} \mathrm{C}$. Significant quadrupole MS operating parameters: interface temperature, $250^{\circ} \mathrm{C}$; ion source temperature, $200^{\circ} \mathrm{C}$; electron impact ionization at $70 \mathrm{eV}$ with $0.9 \mathrm{kV}$ detector voltage, a scan mass range of $50-800$ at a sampling rate of $1.0 \mathrm{scan} /$ second, scan speed: $1428 \mathrm{u} /$ second, and interval: 0.3 seconds.

\section{Result and Discussion}

In order to evaluate the impact of different extraction techniques on the chemical composition of EOS from tamarind seed, Soxhlet extraction and hydrodistillation with the Clevenger were used. For each extraction technique, the total yield was defined as gram of oil extracted per $\mathrm{kg}$ of dried pulverised seed filled into the extraction apparatus. The moisture content of the seed was determined before pulverising, and it gives an approximate value of $8.2 \%$ d.b. The techniques used are first compared in terms of the yield. It was observed that SE yielded more oil than the HDC as shown in Table 1. This could be due to the long period of extraction of SE $(6 \mathrm{~h})$ compared to HDC $(3 \mathrm{~h})$. It is noteworthy to point out the reason for the different extraction time used. For Soxhlet extraction, there are minimum numbers of cycles that are required (16 cycles), and it takes between 6 and $8 \mathrm{~h}$ [22]. Both methods produced a yellowish color of EOS with unpleasant odour. Extraction time is one of the important parameters usually considered for ultimate yield. This allows for sufficient degradation of the plant tissue structure and the release of adequate volatile compounds such as essential oils. Similarly, results have been reported in the literature [23].

The compounds obtained in HDC extraction were identified early in the GC-MS quantification compared to the separation pattern obtained in the SE (Figures 1 and 2). This shows that the HDC extraction process promotes compounds with low solubility and less molecular weight while SE favours high solubility and higher-molecularweight volatile compounds. This agrees with the report of Sermakkani and Thangapandian [24] indicating that highermolecular-weight compounds are less volatile. Compounds with higher molecular weight require high temperature for their elution. It is interesting to know that 32 different compounds were exceptional to only the hydrodistillation method and 31 compounds were unique to the SE methods, while 6 compounds were found in both methods. Moreover, the results from Table 2 showed that the chemical constituents of the essential oils by the two methods (HDC and SE) were similar with minor quantitative variances. The predominant compounds in SE were beta-sitosterol (12.71\%), oleic acid (4.54\%), gamma-tocopherol (5.2\%), cis-vaccenic acid (17.6\%), 9,12-octadecadienoic acid (Z, Z)- (11.82\%), nhexadecanoic acid (8.16\%), and 9,12-octadecadienoic acid and methyl ester (5.84\%), while the predominant ones in HDC include beta-sitosterol (4.54\%), $n$-hexadecanoic acid (11.53\%), 9,12-octadecadienoic acid (Z, Z)- (23.72\%), and cis-vaccenic acid (17.16). The presence of these compounds is in agreement with previous reports on Tamarindus indica though at different concentrations $[25,26]$. Six major compounds, p-xylene, gamma-tocopherol, 2-methyltetracosane, 9,12-octadecadienoic acid (Z, Z)-, n-hexadecanoic acid, and beta-sitosterol, were found in both extraction processes, with beta-sitosterol having the highest proportion $(12.71 \%)$ in the SE $(4.53 \%)$ obtained with the HDC process. Also, the percentage of some fatty acid octadecadienoic acid (commonly known as oleic acid) quantified in SE is $4.54 \%$, while HDC has $3.81 \%$ is noticeable variance in both methods. However, another fatty acid, cisvaccenic acid, was present in almost the same quantity signifying it was not decomposed by heat. The presence of different proportions of beta-sitosterol and gamma-tocopherol observed in this study has been reported by other authors [27-29]. The differences in the proportion obtained could be ascribed to the duration of extraction and the extraction technique implemented.

In addition, 9,12-octadecadienoic acid (Z, Z)- was the most predominant compound in HDC with $23.72 \%$ followed by cis-vaccenic acid with $17.16 \%$ which is in agreement with the report of Mehdi et al. [30] and Abdu [26] on tamarind leaves and seed, respectively. Also, 9,12-octadecadienoic acid $(\mathrm{Z}, \mathrm{Z})$ - has been reported to possess many pharmacological potentials such as antioxidant, antimicrobial, ant-inflammatory, and hepatoprotective. Therefore, its presence in a higher quantity gives the HDC advantage over SE. Though 
TABle 1: Percentage yield of the two methods used.

\begin{tabular}{lccc}
\hline Methods used & Fresh sample $(\mathrm{g})$ & Quantity yield $(\mathrm{g})$ & $\%$ yield \\
\hline Soxhlet & 100 & 2.5 & 2.5 \\
Hydrodistillation with the Clevenger & 100 & 1.4 & 1.4 \\
\hline
\end{tabular}

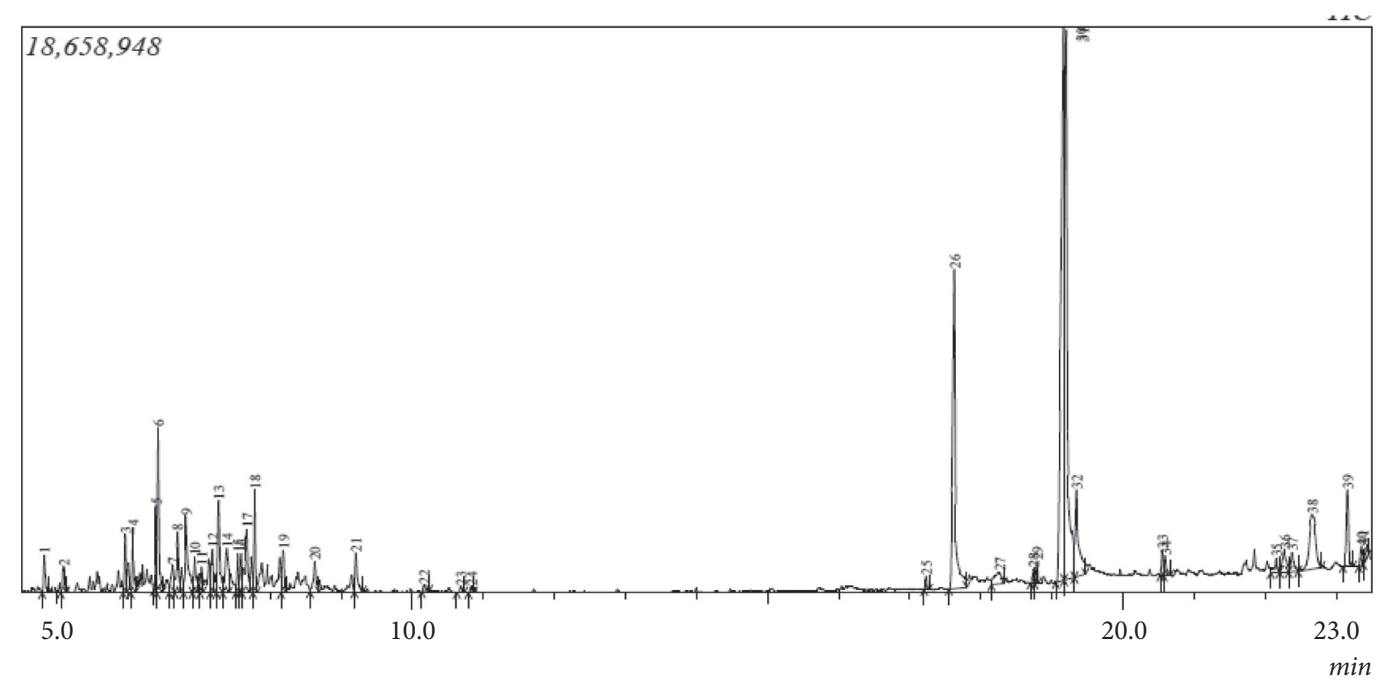

FIgURE 1: Chromatogram of essential oils of tamarind seed extracted with the Clevenger apparatus.

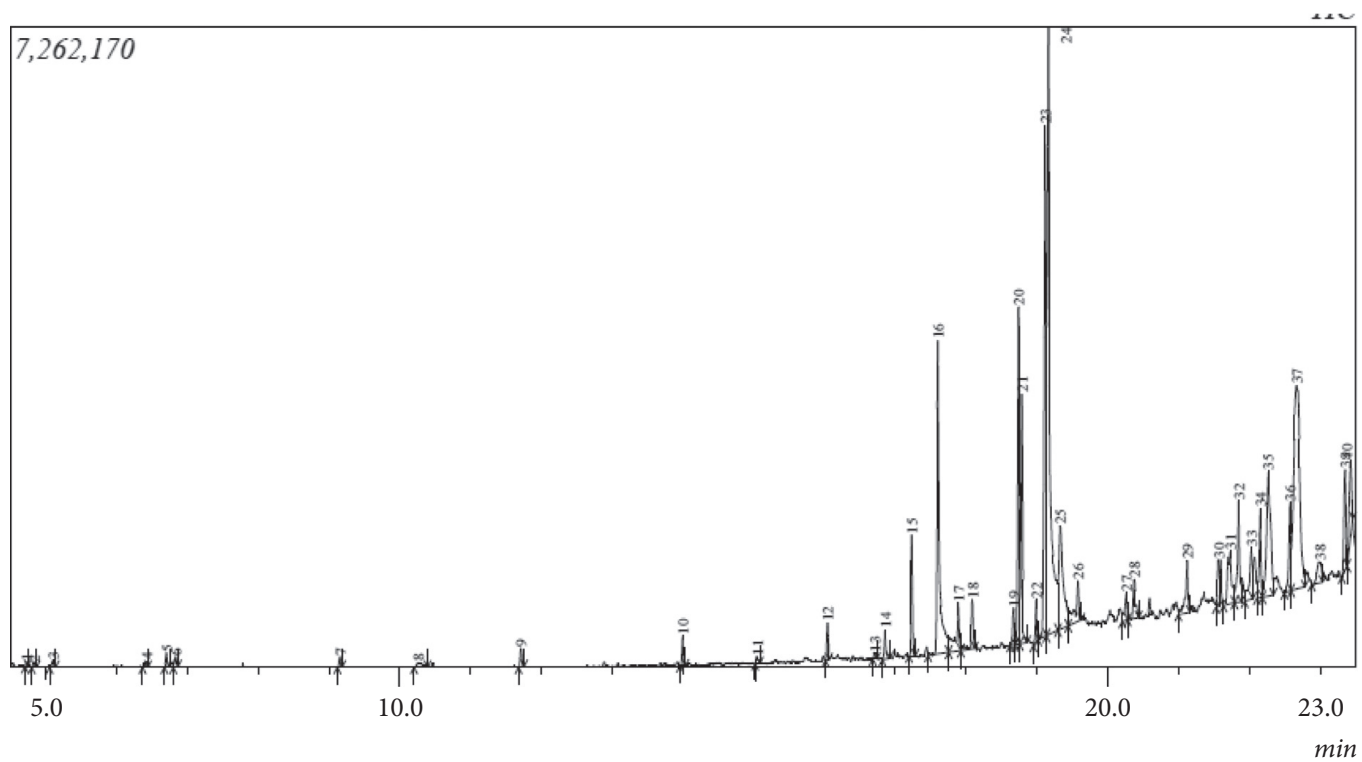

FIgURE 2: Chromatogram of essential oils of tamarind seeds extracted by Soxhlet extraction.

9,12-octadecadienoic acid (Z, Z)- was also found in SE $(11.82 \%)$, it was in lower quantity.

Monoterpene hydrocarbons are not as significant as the oxygenated compounds in the aspect of good fragrance; oxygenated compounds are well known for their pleasant aroma; hence, HDC is better. However, monoterpenes are mostly used for therapeutic treatment such as antibacterial and antifungal agents. Sesquiterpenes also have the potential to be used as anti-inflammatory and anticarcinogenic agents [31].
On the other hand, different types of terpenoid at varying proportions (Table 3) were also identified. Monoterpene hydrocarbons (MHs) $(0.28 \%)$, oxygenated monoterpenes (OMs) (0.14\%), oxygenated sesquiterpenes (OSs) $(0.145 \%)$, terpenes (Ts) $(9.41 \%)$, and oxygenated diterpenes (ODs) $(0.63 \%)$ were found in the SE method. Similarly, monoterpene hydrocarbons (8.2\%), oxygenated monoterpenes (OMs) (2.29\%), and terpenes (1.15\%) were obtained in the HDC process. Notably, two terpenoids (oxygenated sesquiterpenes and oxygenated diterpenes) were observed in 
TABLE 2: Gas chromatography-mass spectrometry result of the EOS of tamarind seed obtained from the two methods.

\begin{tabular}{|c|c|c|c|c|c|}
\hline \multirow{2}{*}{$\mathrm{S} / \mathrm{N}$} & \multirow{2}{*}{ Compounds } & \multirow{2}{*}{ Formulae } & \multirow{2}{*}{ MW } & \multicolumn{2}{|c|}{ Sample \% } \\
\hline & & & & HDC & SE \\
\hline 1 & o-Xylene & $\mathrm{C}_{8} \mathrm{H}_{10}$ & 106 & 0.77 & 0 \\
\hline 2 & p-Xylene & $\mathrm{C}_{8} \mathrm{H}_{10}$ & 106 & 0.75 & 0.08 \\
\hline 3 & Hydrazinecarboxylic acid, phenylmethyl est & $\mathrm{C}_{8} \mathrm{H}_{10} \mathrm{~N}_{2} \mathrm{O}_{2}$ & 166 & - & 0.06 \\
\hline 4 & 3-tert-Butyl-5-chloro-2-hydroxybenzophenone & $\mathrm{C}_{17} \mathrm{H}_{17} \mathrm{ClO}_{2}$ & 288 & 1.29 & - \\
\hline 5 & Benzeneethanol,alpha-, beta-dimethyl- & $\mathrm{C}_{10} \mathrm{H}_{14} \mathrm{O}$ & 150 & - & 0.14 \\
\hline 6 & Benzene, 1,2,4-trimethyl & $\mathrm{C}_{9} \mathrm{H}_{12}$ & 120 & 1.34 & - \\
\hline 7 & Benzene, 1,2,3-trimethyl & $\mathrm{C}_{9} \mathrm{H}_{12}$ & 120 & - & 0.16 \\
\hline 8 & Dodecane & $\mathrm{C}_{12} \mathrm{H}_{26}$ & 170 & 1.6 & - \\
\hline 9 & Dodecane & $\mathrm{C}_{9} \mathrm{H}_{12}$ & 120 & 3.08 & - \\
\hline 10 & 1-Decyne & $\mathrm{C}_{10} \mathrm{H}_{18}$ & 138 & - & 0.2 \\
\hline 11 & 1-Hexanol, 2-ethyl- & $\mathrm{C}_{8} \mathrm{H}_{18} \mathrm{O}$ & 130 & - & 0.19 \\
\hline 12 & $2 \mathrm{H}$-pyran, tetrahydro-4-methyl-2-(2-methyl & $\mathrm{C}_{10} \mathrm{H}_{18} \mathrm{O}$ & 154 & 1.04 & - \\
\hline 13 & Oxalic acid, isobutyl nonyl ester & $\mathrm{C}_{15} \mathrm{H}_{28} \mathrm{O}_{4}$ & 272 & - & 0.14 \\
\hline 14 & cis-3-Methylcyclohexanol & $\mathrm{C}_{7} \mathrm{H}_{14} \mathrm{O}$ & 114 & 1.67 & - \\
\hline 15 & 2-Oxepanone, 7-methyl- & $\mathrm{C}_{7} \mathrm{H}_{12} \mathrm{O}_{2}$ & 128 & - & 0.28 \\
\hline 16 & Benzene, 1,2,3-trimethyl- & $\mathrm{C}_{9} \mathrm{H}_{12}$ & 120 & 2.75 & - \\
\hline 17 & Tridecane & $\mathrm{C}_{13} \mathrm{H}_{28}$ & 184 & - & 0.3 \\
\hline 18 & Cyclohexane, (1-methylpropyl)- & $\mathrm{C}_{10} \mathrm{H}_{20}$ & 140 & 1.09 & - \\
\hline 19 & 2-Bromo dodecane & $\mathrm{C}_{12} \mathrm{H}_{25} \mathrm{Br}$ & 248 & - & 0.47 \\
\hline 20 & Benzene, 2-propenyl- & $\mathrm{C}_{9} \mathrm{H}_{10}$ & 118 & 0.55 & - \\
\hline 21 & Sulfurous acid, 2-propyl tridecyl ester & $\mathrm{C}_{16} \mathrm{H}_{34} \mathrm{O}_{3} \mathrm{~S}$ & 306 & - & 0.16 \\
\hline 22 & Benzene, 1-methyl-3-propyl & $\mathrm{C}_{10} \mathrm{H}_{14}$ & 134 & 1.55 & - \\
\hline 23 & Hexadecane & $\mathrm{C}_{16} \mathrm{H}_{34}$ & 226 & - & 0.55 \\
\hline 24 & Spiro[3.5]nona-5,7-dien-1-one, 5,9,9-trimet & $\mathrm{C}_{12} \mathrm{H}_{16} \mathrm{O}$ & 176 & 2.39 & - \\
\hline 25 & Vinyl 10-undecenoate & $\mathrm{C}_{13} \mathrm{H}_{22} \mathrm{O}_{2}$ & 210 & - & 0.11 \\
\hline 26 & Naphthalene, decahydro-, trans & $\mathrm{C}_{10} \mathrm{H}_{18}$ & 138 & 1.75 & - \\
\hline 27 & 1-Hexadecanol & $\mathrm{C}_{16} \mathrm{H}_{34} \mathrm{O}$ & 242 & - & 0.54 \\
\hline 28 & Bicyclo[3.1.1]hept-2-en-6-ol, 2,7,7-trimeth & $\mathrm{C}_{12} \mathrm{H}_{18} \mathrm{O}_{2}$ & 194 & 0.93 & - \\
\hline 29 & Hexadecanoic acid, methyl ester & $\mathrm{C}_{16} \mathrm{H}_{32} \mathrm{O}_{2}$ & 256 & - & 1.18 \\
\hline 30 & p-Cymene & $\mathrm{C}_{10} \mathrm{H}_{14}$ & 134 & 0.84 & - \\
\hline 31 & $n$-Hexadecanoic acid & $\mathrm{C}_{16} \mathrm{H}_{32} \mathrm{O}_{2}$ & 256 & - & 8.16 \\
\hline 32 & Benzene, 1-ethyl-2,3-dimethyl & $\mathrm{C}_{10} \mathrm{H}_{14}$ & 134 & 2.22 & - \\
\hline 33 & Tritetracontane & $\mathrm{C}_{43} \mathrm{H}_{88}$ & 604 & - & 1.69 \\
\hline 34 & Undecane & $\mathrm{C}_{11} \mathrm{H}_{24}$ & 156 & 1.97 & - \\
\hline 35 & i-Propyl 14-methyl-pentadecanoate & $\mathrm{C}_{19} \mathrm{H}_{38} \mathrm{O}_{2}$ & 298 & - & 1 \\
\hline 36 & Benzene, 1,2,4,5-tetramethyl- & $\mathrm{C}_{10} \mathrm{H}_{14}$ & 134 & 1.11 & - \\
\hline 37 & 1-Eicosanol & $\mathrm{C}_{20} \mathrm{H}_{42} \mathrm{O}$ & 298 & - & 0.63 \\
\hline 38 & 2,4-Dimethylstyrene & $\mathrm{C}_{10} \mathrm{H}_{12}$ & 132 & 0.21 & - \\
\hline 39 & 9,12-Octadecadienoic acid, methyl ester & $\mathrm{C}_{19} \mathrm{H}_{34} \mathrm{O}_{2}$ & 294 & - & 5.84 \\
\hline 40 & 2-Naphthalenol, 1,2-dihydro-, acetate & $\mathrm{C}_{12} \mathrm{H}_{12} \mathrm{O}_{2}$ & 188 & 1.07 & - \\
\hline 41 & 11-Octadecenoic acid, methyl ester & $\mathrm{C}_{19} \mathrm{H}_{36} \mathrm{O}_{2}$ & 296 & - & 3.94 \\
\hline 42 & Nonanoic acid & $\mathrm{C}_{9} \mathrm{H}_{18} \mathrm{O}_{2}$ & 158 & 0.26 & - \\
\hline 43 & Tetradecanoic acid, 12-methyl-, methyl ester & $\mathrm{C}_{16} \mathrm{H}_{32} \mathrm{O}_{2}$ & 256 & - & 0.65 \\
\hline 44 & Naphthalene, 2-methyl- & $\mathrm{C}_{11} \mathrm{H}_{10}$ & 142 & 0.14 & - \\
\hline 45 & 9,12-Octadecadienoic acid (Z, Z)- & $\mathrm{C}_{18} \mathrm{H}_{32} \mathrm{O}_{2}$ & 280 & - & 11.82 \\
\hline 46 & 2,4-Decadienal, (E, E)- & $\mathrm{C}_{10} \mathrm{H}_{16} \mathrm{O}$ & 152 & 0.16 & - \\
\hline 47 & cis-Vaccenic acid & $\mathrm{C}_{18} \mathrm{H}_{34} \mathrm{O}_{2}$ & 282 & 17.16 & 17.6 \\
\hline 48 & Hexadecanoic acid, methyl ester & $\mathrm{C}_{17} \mathrm{H}_{34} \mathrm{O}_{2}$ & 270 & 0.26 & - \\
\hline 49 & Oleic acid & $\mathrm{C}_{18} \mathrm{H}_{34} \mathrm{O}_{2}$ & 282 & - & 4.54 \\
\hline 50 & $n$-Hexadecanoic acid & $\mathrm{C}_{16} \mathrm{H}_{32} \mathrm{O}_{2}$ & 256 & 11.53 & - \\
\hline 52 & Phytol, acetate & $\mathrm{C}_{22} \mathrm{H}_{42} \mathrm{O}_{2}$ & 338 & 1.12 & - \\
\hline 53 & 10-Undecen-1-al, 2-methyl & $\mathrm{C}_{12} \mathrm{H}_{22} \mathrm{O}$ & 182 & - & 0.72 \\
\hline 54 & Cyclopropaneoctanoic acid, 2-[[2-[(2-ethyl & $\mathrm{C}_{22} \mathrm{H}_{38} \mathrm{O}_{2}$ & 334 & 0.32 & - \\
\hline 55 & 7-Hexadecenal, (Z)- & $\mathrm{C}_{16} \mathrm{H}_{30} \mathrm{O}$ & 238 & - & 1.02 \\
\hline 56 & 9-Octadecenoic acid (Z)-, methyl ester & $\mathrm{C}_{19} \mathrm{H}_{36} \mathrm{O}_{2}$ & 296 & 0.42 & - \\
\hline 57 & 9,12-Octadecadienoic acid (Z, Z)- & $\mathrm{C}_{18} \mathrm{H}_{32} \mathrm{O}_{2}$ & 280 & 23.72 & \\
\hline 58 & Hexadecanal, 2-methyl- & $\mathrm{C}_{17} \mathrm{H}_{34} \mathrm{O}$ & 254 & - & 0.87 \\
\hline 59 & 1,2-15,16-Diepoxyhexadecane & $\mathrm{C}_{16} \mathrm{H}_{30} \mathrm{O}_{2}$ & 254 & - & 2.25 \\
\hline 60 & Octadecanoic acid & $\mathrm{C}_{18} \mathrm{H}_{36} \mathrm{O}_{2}$ & 284 & 3.81 & - \\
\hline
\end{tabular}


TABLE 2: Continued.

\begin{tabular}{|c|c|c|c|c|c|}
\hline \multirow{2}{*}{$\mathrm{S} / \mathrm{N}$} & \multirow{2}{*}{ Compounds } & \multirow{2}{*}{ Formulae } & \multirow{2}{*}{ MW } & \multicolumn{2}{|c|}{ Sample \% } \\
\hline & & & & HDC & SE \\
\hline 61 & Undecanoyl chloride & $\mathrm{C}_{11} \mathrm{H}_{21} \mathrm{C}_{1 \mathrm{O}}$ & 204 & 0.9 & - \\
\hline 62 & Hexadecanoic acid, 2-hydroxy-1- (hydroxym & $\mathrm{C}_{19} \mathrm{H}_{38} \mathrm{O}_{4}$ & 330 & - & 1.47 \\
\hline 63 & Diisooctyl phthalate & $\mathrm{C}_{24} \mathrm{H}_{38} \mathrm{O}_{4}$ & 390 & 0.53 & 1.76 \\
\hline 64 & gamma-Tocopherol & $\mathrm{C}_{28} \mathrm{H}_{48} \mathrm{O}_{2}$ & 416 & 1.05 & 5.2 \\
\hline 65 & beta-Sitosterol & $\mathrm{C}_{29} \mathrm{H}_{50} \mathrm{O}$ & 414 & 4.53 & 12.71 \\
\hline 66 & Cholest-22-ene-21-ol, 3,5-dehydro-6-metho & $\mathrm{C}_{33} \mathrm{H}_{54} \mathrm{O}_{3}$ & 498 & - & 1.02 \\
\hline 67 & cis-13,16-Docasadienoic acid & $\mathrm{C}_{22} \mathrm{H}_{40} \mathrm{O}_{2}$ & 336 & 1.94 & - \\
\hline 68 & Z, Z-3,13-octadecedien-1-ol & $\mathrm{C}_{18} \mathrm{H}_{34} \mathrm{O}$ & 266 & - & 2.24 \\
\hline \multirow[t]{2}{*}{69} & 9-Octadecenoic acid (Z)-, 2-hydroxy-1-(hyd & $\mathrm{C}_{21} \mathrm{H}_{40} \mathrm{O}_{4}$ & 356 & 0.43 & - \\
\hline & & & Total & 98.25 & 100 \\
\hline
\end{tabular}

MW- molecular weight in gram, HDC- hydrodistillation with the Clevenger, SE- Soxhlet extraction.

Table 3: Different types of terpenoids present in each of the method used for the extraction.

\begin{tabular}{|c|c|c|c|c|}
\hline Terpenoids & SE & Area \% & $\mathrm{HDC}$ & Area $\%$ \\
\hline \multirow{7}{*}{$\begin{array}{l}\text { Monoterpenes hydrocarbons } \\
\text { (MHs) }\end{array}$} & p-Xylene & & & \\
\hline & 0.08 & $\begin{array}{c}\text { o- } \\
\text { Xylene }\end{array}$ & 1.15 & \\
\hline & 1-Decyne & 0.2 & p-Xylene & 1.75 \\
\hline & & & Cyclohexane,(1-methylpropyl)- & 0.84 \\
\hline & & & Benzene, 1-methyl-3-propyl- & 2.22 \\
\hline & & & Naphthalene, 2-methyl- & 1.11 \\
\hline & & & Naphthalene, decahydro-, trans- & 1.21 \\
\hline \multirow{4}{*}{ Oxygenated monoterpenes (OMs) } & $\begin{array}{l}\text { Benzeneethanol, alpha-, beta- } \\
\text { dimethyl- }\end{array}$ & 0.14 & 2,4-Decadienal, (E, E)- & \\
\hline & 0.16 & & \multirow{3}{*}{$\begin{array}{l}\text { Cyclohexane, (1-methylpropyl)- } \\
\text { 2H-pyran, tetrahydro-4-methyl-2-(2- } \\
\text { methyl }\end{array}$} & \\
\hline & & & & 1.09 \\
\hline & & & & 1.04 \\
\hline Oxygenated sesquiterpenes (OSs) & Oxalic acid, isobutyl nonyl ester & 0.14 & \multirow{3}{*}{ 2-Methyltetracosane } & \multirow{3}{*}{1.15} \\
\hline Terpenes & 2-Methyltetracosane & 9.41 & & \\
\hline Oxygenated diterpenes (ODs) & 1-Eicosanol & 0.63 & & \\
\hline
\end{tabular}

the SE process that were not obtained in the HDC process; however, the presence of higher-oxygenated compounds observed in the HDC method indicates the superiority of the oil obtained over SE and could be accredited to small quantity of water content in the system which would have minimized the thermal decomposition of oxygenated compounds when compared with the SE method. A major impact of heat was observed when the quantity of p-xylene was reduced from $1.75 \%$ in HDC to $0.08 \%$ in SE. This is as a result of thermal decomposition by partial dehydrogenation of the methyl groups. Petroleum ether is the best solvent used in research due to its relative cheap cost and low boiling point $\left(30-60^{\circ} \mathrm{C}\right)[32]$, but there was no significant difference in the compounds eluted except for the terpenoids. It can be suggested that the SE techniques using petroleum ether are suitable for the extraction of terpenoid portion from tamarind plant seeds. The observed variation in the terpenoid type and proportion could be attributed to the operational temperature, solvent used, and the process duration.

Comparing the outcome of this study with some earlier report on the same plant (tamarind), there were significant differences in both qualitative and quantitative proportion obtained. These variance could be attributed to many factors including chemical reactions such as thermal degradation, allylic rearrangement, hydrolysis, and oxidation, which are instigated and heightened due to the impact of high temperatures and water content. Other factors that are likely to be responsible are the genotype of the plant, geographic location of the plant, and mode of extraction [33].

\section{Conclusions}

From the data obtained in this study, it is observed that the volatile compounds of the essential oil obtained from Tamarindus indica seeds depend on the method utilized for the extraction. This buttresses the fact that the chemical composition of essential oils relies on the type of extraction methods applied. The Soxhlet extraction method (SE) resulted in higher yields in terms of quantity but lower quality due to low amount of oxygenated compounds than that obtained from hydrodistillation using the Clevenger method. Some compounds identified showed no substantial differences as far as the method applied was concerned, while others produced higher contents with a particular technique. Apparently, the composition of volatiles compounds is significantly affected by extraction techniques. In 
conclusion, the HDC method is considered a better method for the extraction of qualitative essential oil from the seed of Tamarindus indica.

\section{Data Availability}

Data are available within the manuscript.

\section{Conflicts of Interest}

The authors declare no conflicts of interest.

\section{References}

[1] O. R. Alara, N. H. Abdurahman, C. I. Ukaegbu, and N. A. Kabbashi, "Extraction and characterization of bioactive compounds in Vernonia amygdalina leaf ethanolic extract comparing Soxhlet and microwave-assisted extraction techniques," Journal of Taibah University for Science, vol. 13, no. 1, pp. 414-422, 2019.

[2] F. Martinello, V. Kannen, J. J. Franco et al., "Chemopreventive effects of a Tamarindus indica fruit extract against colon carcinogenesis depends on the dietary cholesterol levels in hamsters," Food and Chemical Toxicology, vol. 107, pp. 261-269, 2017.

[3] G. Anywar, E. Kakudidi, R. Byamukama, J. Mukonzo, A. Schubert, and H. Oryem-Origa, "Indigenous traditional knowledge of medicinal plants used by herbalists in treating opportunistic infections among people living with HIV/AIDS in Uganda," Journal of Ethnopharmacology, vol. 246, pp. 112-205, 2020.

[4] M. Vaziri, A. H. Dehkordi, and N. Ebrahimi, "The effects of Boswellia (Frankincense) gel and hydrocolloid dressing on healing of second-and third-degree pressure ulcers among hospitalized patients," Journal of Herbal Medicine, vol. 29, Article ID 100461, 2021.

[5] D. Kumar, S. Rawat, and R. Joshi, "Predicting the current and future suitable habitat distribution of the medicinal tree Oroxylum indicum (L.) Kurz in India," Journal of Applied Research on Medicinal and Aromatic Plants, vol. 23, Article ID 100309, 2021.

[6] B. Panchal, S. Deshmukh, and M. Sharma, "Optimization of oil extraction and characterization from Tamarindus indica Linn seed oil," International Journal of Oil, Gas and Coal Engineering, vol. 2, no. 1, pp. 1-6, 2014.

[7] E. Ebifa-Othieno, A. Mugisha, P. Nyeko, and J. D. Kabasa, "Knowledge, attitudes and practices in tamarind (Tamarindus indica L.) use and conservation in Eastern Uganda," Journal of Ethnobiology and Ethnomedicine, vol. 13, no. 1, pp. 1-13, 2017.

[8] N. Isnaini, S. Songkro, N. Kaewnopparat, and D. Maneenuan, "Formulation and investigation of antioxidant potential of o/ w lotions containing Tamarindus indica l. fruit pulp extract," MATTER: International Journal of Science and Technology, vol. 5, no. 2, pp. 100-112, 2019.

[9] S. S. Bhadoriya, A. Ganeshpurkar, J. Narwaria, G. Rai, and A. P. Jain, "Tamarindus indica: extent of explored potential," Pharmacognosy Reviews, vol. 5, no. 9, p. 73, 2011.

[10] J. S. Raut and S. M. Karuppayil, "A status review on the medicinal properties of essential oils," Industrial Crops and Products, vol. 62, pp. 250-264, 2014.

[11] Z. A. Aziz, A. Ahmad, S. H. M. Setapar et al., "Essential oils: extraction techniques, pharmaceutical and therapeutic potential-a review," Current Drug Metabolism, vol. 19, no. 13, pp. 1100-1110, 2018.
[12] T. Lefebvre, E. Destandau, and E. Lesellier, "Selective extraction of bioactive compounds from plants using recent extraction techniques: a Review," Journal of Chromatography A, vol. 1635, Article ID 461770, 2020.

[13] M. G. Chacón-Fernández, M. R. Hernández-Medel, M. Bernal-González, M. C. Durán-Domínguez-de-Bazúa, and J. A. Solís-Fuentes, "Composition, properties, stability and thermal behavior of tamarind (Tamarindus indica) seed oil," Grasas Y Aceites, vol. 70, no. 4, p. 333, 2019.

[14] R. Rajput, J. Mishra, R. K. Sharma, and K. Misra, "Characterization techniques for herbal products," in Management of High Altitude Pathophysiology, pp. 171-202, Academic Press, Cambridge, MA, USA, 2018.

[15] M. O. Nafiu, A. A. Hamid, H. F. Muritala, and S. B. Adeyemi, "Preparation, standardization, and quality control of medicinal plants in Africa," Medicinal Spices and Vegetables from Africa, pp. 171-204, 2017.

[16] Y. C. Wong, M. Y. Ahmad-Mudzaqqir, and W. A. WanNurdiyana, "Extraction of essential oil from cinnamon (Cinnamomum zeylanicum)," Oriental Journal of Chemistry, vol. 30, no. 1, p. 37, 2014.

[17] R. Ashraf, S. Ghufran, S. Akram, M. Mushtaq, and B. Sultana, "Cold pressed coriander (Coriandrum sativum L.) seed oil," in Cold Pressed Oils, pp. 345-356, Academic Press, 2020.

[18] A. Oreopoulou, D. Tsimogiannis, and V. Oreopoulou, "Extraction of polyphenols from aromatic and medicinal plants: an overview of the methods and the effect of extraction parameters," Polyphenols in Plants, pp. 243-259, 2019.

[19] Q. W. Zhang, L. G. Lin, and W. C. Ye, "Techniques for extraction and isolation of natural products: a comprehensive review," Chinese Medicine, vol. 13, no. 1, pp. 1-26, 2018.

[20] Association of Official Analytical Chemists, Extraction of Oil Content, Standard Method, Association of Official Analytical Chemists, Washington, DC., USA, 1990.

[21] M. Elyemni, B. Louaste, I. Nechad et al., "Extraction of essential oils of Rosmarinus officinalis L. by two different methods: hydrodistillation and microwave assisted hydrodistillation," Science World Journal, vol. 2019, Article ID 3659432, 6 pages, 2019.

[22] N. H. Snow, Basic Multidimensional Gas Chromatography, Academic Press, Cambridge, Massachusetts, 2020.

[23] F. N. Idris and M. Mohd Nadzir, "Comparative studies on different extraction methods of Centella asiatica and extracts bioactive compounds effects on antimicrobial activities," Antibiotics, vol. 10, no. 4, p. 457, 2021.

[24] M. Sermakkani and V. Thangapandian, "GC-MS analysis of Cassia italica leaf methanol extract," Asian Journal of Pharmaceutical and Clinical Research, vol. 5, no. 2, pp. 90-94, 2012.

[25] P. M. C. L. Reis, C. Dariva, G. A. B. Vieira, and H. Hense, "Extraction and evaluation of antioxidant potential of the extracts obtained from tamarind seeds (Tamarindus indica), sweet variety," Journal of Food Engineering, vol. 173, pp. 116-123, 2016.

[26] B. Abdu, "Comparative study of antimicrobial potentials of seed oils of jatropha curcas and Tamarindus indica," International Journal of Scientific Research in Science, Engineering and Technology, 2019.

[27] E. U. Uzukwu, A. B. Shori, and A. S. Baba, "Phytochemistry and medicinal uses of Tamarindus indica and Persea Americana as sources of plant nutrients," American Journal of Plant Biology, vol. 1, no. 1, pp. 30-34, 2016.

[28] S. S. Shaikh, K. J. Shivsaran, R. K. Pawar, N. S. Misal, H. R. Mene, and B. A. More, "Tamarind seed polysaccharide: a versatile pharmaceutical excipient and its modification," 
International Journal of Pharmaceutical Sciences Review and Research, vol. 33, pp. 157-164, 2015.

[29] D. S. Souza, C. A. Ballus, W. D. S. Oliveira, J. Teixeira Filho, and H. T. Godoy, "Quantitative profile of fatty acids and tocopherols in tamarind seeds (Tamarindus indica L.) from different states of Brazil," Research Journal of Phytochemistry, vol. 11, no. 3, pp. 118-128, 2017.

[30] M. A. H. Mehdi, A. H. M. Al-Alawi, A. Z. A. Thabet, F. Y. Alarabi, G. M. N. Omar, and V. Pradhan, "Analysis of bioactive chemical compounds of leaves extracts from Tamarindus indica using FT-IR and GC-MS spectroscopy," Asian Journal of Research in Biochemistry, vol. 8, no. 1, pp. 22-34, 2021.

[31] D. Vidic, A. Čopra-Janićijević, M. Miloš, and M. Maksimović, "Effects of different methods of isolation on volatile composition of Artemisia annua L," International Journal of Analytical Chemistry, vol. 2018, Article ID 9604183, 6 pages, 2018.

[32] M. K. Abu-Arabi, M. A. Allawzi, H. S. Al-Zoubi, and A. Tamimi, "Extraction of jojoba oil by pressing and leaching," Chemical Engineering Journal, vol. 76, no. 1, pp. 61-65, 2000.

[33] R. Retnosari, S. Marfu'ah, and F. Fajaroh, "Fatty acids in Tamarindus indica L. Seeds oil and antibacterial activity assay," in Key Engineering Materials, vol. 811, pp. 40-46, Trans Tech Publications Ltd, 2019. 